\title{
On Nominalization Metaphor and Its Discourse Function
}

\author{
Minggao Wei \\ College of Foreign Languages, University of Shanghai for Science and Technology, 200093, Shanghai \\ Gaofeng Yu \\ College of Foreign Languages, University of Shanghai for Science and Technology, 200093, Shanghai
}

\begin{abstract}
According to systematic-functional grammar, nominalization is an important source from which grammatical metaphor derives. Starting from the concept of nominalization, this paper, based on a great number of examples, attempts to discuss the following three issues: definition of nominalization; classification of nominalization and its discourse function, and points out that the use of nominalization can add objectivity, conciseness, precision, cohesion and coherence to English discourse.
\end{abstract}

Index Terms - nominalization, grammatical metaphor, discourse function

\section{INTRODUCTION}

Nominalization metaphor is one of the most common features in human daily language use, and is the main manifestation of conceptual metaphor in systemic functional grammar metaphor. Due to the accuracy, objectivity and scientificity of EST texts, nominalization metaphor has become one of the important features of EST language. The study of the characteristics of EST from the perspective of grammatical metaphor theory in systemic functional linguistics provides a new perspective for the study of EST discourse. This paper intends to discuss the phenomenon of nominalized metaphor in scientific English discourse from the perspective of systemic functional linguistics, and analyze the textual function of nominalized metaphor in scientific English.

Halliday put forward the concept of grammatical metaphor for the first time in his book an Introduction to Functional Grammar published in 1985 to explain the complex relationship between the form and function of language. Since then, a large number of related articles have emerged at home and abroad, covering the nature, type, function, manifestation and action mechanism of grammatical metaphor. According to the viewpoint of systemic functional linguistics, the language system consists of phonology, lexicogrammar and discourse semantics, which are the relations between symbol and being symbolized or embodied. Specifically, phonological layer is the embodiment of lexical grammar layer, and lexical grammar layer is the embodiment of discourse meaning layer (Zhu, 2006, p.83-90). There are two ways to embody it: congruent form and non-consistent form. Halliday believes that grammatical metaphor is not only the variation of vocabulary, but also the variation of grammatical components and grammatical structures. He also called the "literal" meaning with strong metaphor-"inconsistent" as "metaphorical form". In the process of communication, the speaker decides whether to express himself metaphorically or consistently according to the situational context. It can be said that metaphorical use is a semantic choice. Halliday divides grammatical metaphor into conceptual metaphor and interpersonal metaphor. The main manifestation of conceptual metaphor is nominalization in language (Zhu, 2004, p.342). Starting with nominalization grammatical metaphor, this paper discusses the definition, types of nominalization and its constructive function for discourse.

According to the viewpoint of systemic functional linguistics, the language system consists of phonology, lexicogrammar and discourse semantics, which are the relations between symbol and being symbolized or embodied. Specifically, phonological layer is the embodiment of lexical grammar layer, and lexical grammar layer is the embodiment of discourse meaning layer ${ }^{[1]}$. However, this embodiment is not always one-to-one and sometimes one meaning can be embodied in several forms and one form can embody several meanings. Halliday divides the expressive relationship between vocabulary, grammar and semantics into congruent form relation and incommensurate form relation. The so-called consistent relation refers to a natural relation between semantic and grammatical categories, while the non-consistent relation refers to the non-naturalization of the relation between semantic and category. For example, in the transitive system of conceptual function, if the process is embodied by verb phrases, the participants are embodied by noun phrases, the features are embodied by adjectives, and logical relations such as time or result are embodied by conjunctions, this is a consistent relation. If the process and characteristics are embodied by noun phrases and the logical relationship is embodied by noun phrases, verb phrases or prepositional phrases, this is the non-consistent relationship, namely metaphorical expression. Hu Zhuanglin, a well-known linguist in China, believes that nominalization refers to the metaphorical process and characteristics. Instead of representing the process or acting as a garnish by clauses, nominalization reflects participants in the form of nouns ${ }^{[2]}$. 


\section{DEFINITION AND TyPES OF NOMINALIZATION}

\section{A. Definition of Nominalization}

Nominalization is a common phenomenon in English usage. Quark et al. (1985) have defined nominalization from the perspective of part-of-speech conversion. They regard nominalization as "a noun phrase corresponding to clause predicate in morphology" (Quirk, 1985). Some people also regard nominalization as a linguistic phenomenon in which verbs or adjectives are used as nouns. Langacker believed that nouns are symbolic structures that can assign semantic poles to things. They show a group of related entities, not the relationships between entities (Langacker, 1991). Modern linguistic dictionaries define nominalization as the process of forming a noun from some other part of speech or the process of deriving a noun phrase from a bottom clause. We believe that nominalization is a process in which the process (the consistent form of its lexical and grammatical level is a verb) and the characteristic (the consistent form is an adjective) are metaphorically transformed so that they are not processes or modifiers in clauses but objects embodied in the form of nouns (Hu, 2004, p.171). In essence, the process of nominalization is the process of linguistic form or grammaticalization. From the perspective of semantic function, nominalization is to regard a certain process or feature as something, and part-of-speech conversion is only one way to realize this phenomenon (Zhu, 2006, p.83-90).

\section{B. Types of Nominalization}

Professor Zhu Yongsheng, a famous linguist in China, divides nominalization into the following three types: regard process as things; regard characteristics as things and evaluation as things.

1. See a process as a thing

Think of the process as something that can be represented by verbs or nouns. In the consistent form, the process is embodied by verbs, while in the non-consistent form, the process is embodied by nouns or noun phrases. In other words, the speaker regards the process as a thing.

For example :

1. (A) The witness described the murderer in great detail.

(B) The witness gave a detailed description of the murderer.

2. (A) We can improve its performance when we use super-heated steam.

(B) An improvement of its performance can be effected by the use of super-heated steam.

3. (A) The floods considerably eroded the land.

(B) There was considerable erosion of the land from the floods.

4. (A) First, John reviewed how the dorsal fin evolved.

(B) There was a first review of the evolution of the dorsal fin.

5. (A) A perpetrator grossly violates human rights.

(B) A gross violation of human rights by a perpetrator.

The italicized parts in example (B) above are all converted from verbs in example (A). This transformation belongs to Halliday's conceptual metaphor. This kind of metaphor has the following three functions: (a) by recategorization, the original dynamic process is transformed into static state, which provides a different abnormal way for people to recognize the world, such as the (B) sentence in the above examples; (b) Through the dynamic process of nominalization, the grammatical features of English noun phrases containing several modifying elements are utilized, that is, the conceptual meaning of noun phrases is greatly or even infinitely expanded through the multi-structural modification of noun phrases, so as to achieve the purpose of concentrating information or classifying things, such as Consensus in Example 3(B) and First Review in Example 4(B); (c) Using the feature that English noun phrases can not contain personal pronouns, the writer is made more objective by grammaticalizing the agent and hiding the implementer. For example, in Example 3(B), the implementer (John) in Example 3(A) is changed into the environmental component from the floods by nominalization in Example 4(B), and the implementer (John) in Example 4(A) is completely omitted by nominalization in review.

2. Regard features as things

To regard features as things can be embodied by adjectives or nouns and noun phrases. In the consistent form, the process is represented by adjectives, while in the non-consistent form, the process is represented by nouns or noun phrases. That is to say, the speaker regards features as things.

Examples:

6. (A) She was narrow-minded and I don't like it.

(B) I don't like her narrow-mindedness.

7. (A) He was hungry to be successful.

(B) He was born with a hunger to be successful.

8. (A) Because technology is getting better, we are able to write work report faster.

(B) Advances in technology are speeding up the writing of work report.

9. (A) It is doubtful how accurate the experiment results are.

(B) The accuracy of the experiment results is doubtful.

The italicized parts in the above example (B) are all converted from adjectives in example (A). This transformation also belongs to Halliday's conceptual metaphor category. Different from the previous category, in this kind of 
transformation process, a certain feature of the thing itself is transformed into the thing, which transforms the originally static and abstract relationship into an entity that can be grasped, such as the (B) sentence in the above examples. It should be noted that once a certain feature is regarded as a thing, the nominalization reflecting these things will change from a feature to an environmental component, such as hunger in example 7(B), or directly into a participant, such as narrow-mindedness in example 6(B) and accuracy in example 9(B), while the carrier of some features will become a modifier of the participant, such as she in example 6(A) and her in sentence 6(B), thus weakening the component of the carrier in the clause information structure.

3. Regard evaluation as a thing

The evaluation can be seen as something embodied by modal verbs, modal adverbs or nouns. In the consistent form, the evaluation meaning is embodied by modal verbs or modal adverbs, while in the non-consistent form, the evaluation meaning is embodied by nouns. That is to say, the speaker regards evaluation as something.

For example:

10. (A) We achieved what we could.

(B) We achieved what our potential.

11. (A) You can go to see the film now.

(B) You have got my permission to go to see the film now.

12. (A) That's what we should do.

(B) It is our obligation to do that.

13. (A) You must pay the bill.

(B) It is your responsibility to pay the bill.

This kind of phenomenon is different from the first two. It belongs to the category of interpersonal metaphor mentioned by Halliday. It can be seen that modal verbs not only have different meanings, but also have obvious differences in the speaker's attitude. For example, could in 10(A) indicates a capability, can in 11(A) indicates permission, and should in 12(A) indicates an obligation. Must in 13(A) shows the strongest intensity, while could shows the weakest intensity. It should be noted that these modal verbs have the characteristics of informal style and colloquialism, while the corresponding nominalization is very formal and serious. Because such differences will lead to different interpersonal meanings, it will affect the establishment and maintenance of interpersonal relationships among discourse participants to a certain extent, thus affecting the ultimate realization of communicative purposes (Zhu, 2006, p.83-90).

\section{TeXtual Functions of Nominalized Grammatical Metaphor}

According to Halliday's point of view, in the process of nominalization of process, features or modal verbs and modal adverbs, in addition to maintaining the original consistent meaning, metaphorical meaning as " things" has been added. Nominalized grammatical metaphor is widely used and relatively complicated in written texts. That is to say, if more nouns or noun phrases are used in a text, the text belongs to a written text, whereas if nouns or noun phrases are used less, the text belongs to a spoken text. Wang Jin-jun counted the total number of small sentences and nominalization structures in five different types of texts through corpus. he concluded that the proportion of nominalization is proportional to the formal degree of text types, that is, the higher the proportion of nominalization, the higher the formal degree of text, and vice versa (Wang, 2003, p.74-78). According to statistical data, the nominalization ratio of scientific and legal texts is the highest, reaching more than $70 \%$, while the nominalization ratio of news English texts is quite different from that of scientific and legal texts, but the nominalization ratio of news English texts is as high as $13 \%$ than that of novels, and there is almost no nominalization structure in fairy tales and fables. This is enough to show that nominalization ratio is closely related to text type. Generally speaking, the more technical a text is, the more frequently it is nominalized. In other words, the more nominalization is used, the more technical and formal the text is. The textual function of nominalized grammatical metaphor is mainly embodied in the following aspects: conciseness, formal function, objective function, cohesion and coherence.

\section{A. Concise and Formal Functions}

Nominalized grammatical metaphor makes the original clauses "packaged" into part-of-speech phrases, and several clauses "packaged" into one clause. The number of sentences in the text is relatively reduced, but the amount of information contained in each sentence is relatively increased (Zhu, 1994, p.8-13). Therefore, it can be said that under the condition of the same amount of information, the use of nominal grammatical metaphor can make the text structure more concise and compact, and express more information in a more refined language.

For example:

14. (A) In the early days when engineers had to make a bridge across a valley and the valley had a river flowing through it they often built viaducts which were constructed of masonry and had numerous arches in them; and many of these viaducts became notable.

(B) In bridging river valleys the early engineers built many notable masonry viaducts of numerous arches.

The above two sentences A and B convey roughly the same meaning. A sentence is consistent and B sentence is metaphorical. Through comparison, we can see that although the information is roughly the same, the length is quite 
different. A sentence uses a large number of clauses with up to 45 words, and its structure is complex and slow. While sentence B uses nominalized metaphor, packing a large number of clauses into noun phrases with only 15 words. The whole sentence is concise, compact in structure and few in number, which shows how concise it is.

15. (A) She became powerful and popular in phenomenal way, and she became powerless and unpopular in a fantastic way and then she was made politically powerful and popular again even more rapidly and remarkably less than four years before she was assassinated in the autumn of 1984.

(B) Her phenomenal rise to power and popularity was followed by a fantastic fall and then by an even more rapid and remarkable political resurrection less than four years before her assassination in the autumn of 1984 .

Example 15(A) is colloquial, (B) is written, and (B) contains four clauses, describing the political ups and downs of Mrs. Gandhi until her assassination. the clauses are connected by the conjunction and. In the (B) sentence, only one clause is used, and no coordinate conjunction is used. Instead, nominalization metaphor greatly increases the vocabulary density and enriches the text, making it more formal.

\section{B. Objective Function}

Nominalized grammatical metaphor is a process of changing other parts of speech into nouns, especially verbs and adjectives. The result is to "materialize", "olidify" or "statize" the action process or characteristics. In the consistent form, the verb embodiment process usually requires participants, and sometimes requires other additional limiting elements, such as complements, etc. However, in the metaphorical form, nominalization metaphor covers both participants and processes. Therefore, English nominalization can make the process originally embodied by verbs be embodied by nouns. When this process (material process) becomes a participant in another process (relational process), participants related to the old process (material process) can be omitted, thus making the expression more objective and true (Jiang, 2008, p.162-165). In interpersonal metaphor, nominalization of modal verbs or modal adverbs can also increase the objectivity of discourse.

For example:

16. (A) If you expose the item for long, it will rapidly deteriorate.

(B) Prolonged exposure will result in rapid deterioration.

The subject you of the expose in the sentence (A) is highly subjective, while in the nominalized sentence (B), after using exposure, the subjective participant you in the sentence (A) is omitted, making the semantic expression appear more objective and true.

17. (A) You can surely rectify this fault if you insert a slash at that time.

(B) Rectification of this fault is achieved by insertion of a slash.

In sentence 17(A), modal verb can and modal adverb surely are used to stimulate interpersonal meaning and reflect the speaker's subjective judgment. The nominalization in (B) helps the speaker emphasize the objective facts and makes the text appear more fair and objective.

\section{Cohesion and Coherence Function}

Nominalized grammatical metaphor can make the cohesion of the text closer and more appropriate, and make the text more coherent. The textual cohesion function of nominalized grammatical metaphor is usually embodied by " thematic-rheme" cohesion (Fan, 1999, p.2-8). That is to say, a part of the rheme in a small sentence acted by a verb, after nominalization, can act as a part of the rheme in the next small sentence, and can be used as a main rheme, rheme or a constituent of the main rheme and rheme.

For example:

18. (A) Academically, the fact that insects could be sterilized by exposure to X-ray had been known since 1916, when an entomologist by the name of G.A. Runner reported that cigarette beetles could be sterilized by exposure to X-ray.

(B) Academically, the fact that insects could be sterilized by exposure to X-ray had been known since 1916, when an entomologist by the name of G.A. Runner reported such sterilization of cigarette beetles.

The 17(A) sentence is consistent, and its cohesion means is realized by repeating the former clause embedded in the sentence that insects could be sterilized by exposure to $\boldsymbol{X}$-ray, including the verb sterilize. Although the cohesion of the text is achieved, the sentence is long, cumbersome and unclear in level. 17(B) is a metaphorical form with a nominal structure. The clause before the verb sterilize in the sentence is embedded as part of the sentence rheme, and its nominal form sterilization is part of the next clause rheme. Due to the use of nominal metaphorical structures, the cohesion of subordinate clause complexes is compact, concise and distinct (Guo, 2010, p 76-79).

19. When radiation falls on a surface, some of the radiation is reflected and some is absorbed. The absorptivity of a surface is defined as the fraction of the light incident on the surface that is absorbed, and a black body is a surface that has an absorptivity of unity. That is, it absorbs all of the radiation that is incident upon it.

There are six clauses in the text. The themes of the first three clauses are radiation, some of the radiation and some. The messages they convey are about the reflection and refraction of radiation. The theme of the fourth clause, the absorption, is transferred from the rheme of the third clause, that is, the rheme of the third clause becomes the theme of the fourth clause through nominalization, and the focus of the text also shifts to the definition of radiation. From the perspective of information, the known information interacts with the new information. is absorbed is the new information in the third clause. the absorptivity of a surface serves as the theme in the fourth clause as the old 
information to guide the emergence of the next new information, thus realizing the cohesion and coherence of the two clauses (Liu, 2008, p.153-155). It can be seen that nominalized grammatical metaphor can make discourse organization more compact, reasonable and concise.

Nominalization metaphor can make the cohesion of the text closer and more appropriate, thus making the text more coherent. The application of nominalized metaphor makes it possible to construct scientific and technological terms and expand the discussion layer by layer. The high degree of abstraction of the empirical meaning in scientific English texts is due to the fact that scientific texts are the language field of a specific text. They publish scientific research results, promote inventions and inventions, and disseminate scientific and technological knowledge through a series of concepts and propositions. The author often abstracts the attributes, characteristics, actions and processes of relevant things into nouns or noun phrases with higher the information density level. Such nouns or noun phrases can serve as the theme of the text and lead the following development. The textual cohesion function of nominalized metaphor is usually embodied by "thematic-rheme" cohesion. That is to say, a part of the rheme in a small sentence acted by a verb, after nominalization, can act as a part of the rheme in the next small sentence, and can be used as a main rheme, rheme or a constituent of the main rheme and rheme. The thematic structure and the information structure of the clause together make the whole text "focused", deepening in content and expanding in structure, thus realizing cohesion and coherence of the whole text.

\section{CONCLUSION}

Nominalization metaphor is the main feature of scientific and technological discourse and an effective and important means of grammatical metaphor. It plays an extremely important role in scientific and technological discourse. People usually use words to express quantity, such as how many things have been done or how much weight has been occupied, etc. At this time, they need to use words to express quantity. Nominalization metaphor is the best way to embody this quantity. It transforms processes, features, modal verbs and modal adverbs into things, which have the double semantic features of consistency and metaphor, thus affecting the meaning of clauses and texts. Proper use of nominalization can make the discourse appear more objective, formal and concise, and the discourse is more accurate, cohesive, more reasonable and compact, greatly enriching the language system. Nominalized grammatical metaphor is an important feature of formal style. In normal circumstances, the degree of formality in a text is proportional to the frequency with which nominalized grammatical metaphor is used. There are a large number of nominalized metaphors in formal styles such as scientific texts. Therefore, mastering the textual functions of nominalized metaphors in scientific texts can deepen the understanding of the deep semantics of scientific texts, lay a good foundation for the accurate understanding of scientific texts and provide better services for the translation of scientific English.

\section{REFERENCES}

[1] Fan, W. (1999). Textual Cohesion Function of Nominalization Metaphor. Foreign Languages Research, 1, 2-8.

[2] Guo, J. (2010). On Nominalization Metaphor in English for Science and Technology: Discourse Function and Cognitive Effect. Foreign Language and Literature, 2, 76-79.

[3] Hu, Z. (2004). Metaphor and Cognitive. Beijing: Peking University Press, 35.

[4] Jiang, S. (2008). Grammatical Metaphor in English for Science and Technology. Social Sciences in Guangxi, 1, $162-165$.

[5] Liu, X. (2008). On Nominalization in English. Journal of Changsha Railway University (Social Science Edition), 3, $153-155$.

[6] Langacker, R. W. (1991). Foundations of Cognitive Grammar. Redwood City: Stanford University Press.

[7] Quirk, R. et al. (1985). A Comprehensive Grammar of the English Language. London: Longman.

[8] Wang, J. (2003). Nominalization in Text Types. Foreign Language Research, 2, 74-78.

[9] Zhu, Y. (1994). Grammatical Metaphor in English. Journal of Foreign Languages, 1, 8-13.

[10] Zhu, Y. (2006). Nominalization, Verbalization and Grammatical Metaphor. Foreign Language Teaching and Research, 2, 83-90.

[11] Zhu, Y., Yan, S. \& Miao, X. (2004). An Introduction to Functional Linguistics. Shanghai: Shanghai Foreign Language Education Press.

Minggao Wei was born in 1983. He is currently a postgraduate in the College of Foreign Languages, University of Shanghai for Science and Technology, Shanghai, China. His major is Master of Translation and Interpretation.

Gaofeng Yu graduated from Nankai University in 1988. He is currently an Associate Professor at University of Shanghai for Science and Technology. His research interests mainly are cognitive linguistics and translation theory and practice. 